\title{
Research on the Postgraduates' Quality Assurance Based on Cultivation of Innovative Ability
}

\author{
CHEN Guoping \\ Marketing department, School of Management \\ Wuhan University of Science and Technology \\ Wuhan, China \\ E-mail: cgp1717@163.com
}

\author{
LUO Xuan \\ Marketing department, School of Management \\ Wuhan University of Science and Technology \\ Wuhan, China \\ E-mail: 980652034@qq.com
}

\begin{abstract}
In the knowledge-based economy era, postgraduate education shall be based on the cultivation of innovative ability. ${ }^{1}$ In China, the innovative ability of postgraduate students is slightly less inadequate due to various causes. According to the method of system theory, this paper constructs a framework of quality assurance system on the cultivation of postgraduates' innovative ability and proposes some concrete solutions to the quality assurance, such as renewing education ideas, establishing an enrollment mechanism of selecting innovative talents; highlighting the personality development of students; implementing classified cultivation mode and upholding quality concept of pluralism; reforming the teaching methods and contents and promoting seminar-style teaching; creating knowledge innovation mechanism and atmosphere; adopting the regime of tutors collective guidance, stressing the innovative level of dissertation writing.
\end{abstract}

Keywords -Innovative ability; Cultivation of graduates; Quality assurance

\section{INTRODUCTION}

In the 21st century, the competition between countries is comprehensive strength contend. After all, it is a competition of innovation, especially innovative talent. Postgraduate education is the highest level of our national education structure, holding an important position in cultivating highquality, high-level innovative talents for the country's modernization (Wang and Wang, 2012)[4]. With continuing expansion of enrollment of graduate students in China, how to improve the innovative ability of postgraduates while ensuring the quality of cultivation has aroused widespread concern in society. However, how shall we cultivate the innovative ability of postgraduate students?

In general, innovation ability indicates a strong sense of innovation of individual and the ability of defining and analyzing the "not new" accurately and comprehensively within the capacity of individual, the ability of constantly forming and proposing unique ideas and the ability of objectively describing and defining new achievement properly and appropriately as well as a comprehensive ability of integrating these three basic quality. As for graduate students, the innovative ability mainly refers to the ability of discovering

Sponsors: Postgraduate teaching research project by Wuhan university of science and technology (Yjg201408) problems adeptly and having innovation awareness, creative thinking and exploration spirit, and the ability of solving problems creatively with the aid of integrating knowledge.

\section{REPRESENTATIONS AND CAUSES OF INNOVATION ABILITY DEFICIENCY OF POSTGRADUATES IN CHINA}

In China, the innovative ability of postgraduate students is slightly less inadequate. It is mainly reflected in: the students' ability of independent innovative learning is relatively weak; lacking teamwork training and cooperation and innovation capability is relatively insufficient; emphasizing on theoretical research while neglecting first-hand investigation, the ability to find practical problems is not satisfactory; stressing the ideological education and the methodology research methods is less underlined; document retrieval capability is not enough as well.

The above phenomena reflected in the quality of graduate education is that there are considerable number of graduated students lacking innovation ability and innovative awareness that are not able to solve the problems with proper and comprehensive judgment when facing problems. These students are a kind of "reproduced" talents rather than "creative" talents, only suitable for some mechanical work and hard for creative work.

According to Wang Ruifei’s etc. (2010)[7] research finding, the causes of graduate students' insufficiency of innovation ability are varied, mainly encompassing: (1) as for the idea of postgraduate education, too much weight has been placed on common and standardized education while personalized education is inadequate; (2) in terms to selection of students, the assessment emphasize much more on prepared knowledge than overall quality and innovative ability; (3) with respect to education training mechanism, requirement of planning and unidirectional of is much more than flexibility and two-way communication; in respect of coursework, the "warehouse theory" is prevailing over the innovative ability for a long period; (4) in the case of a single tutor training system, the research is confined to the tutor's familiar territory with narrow academic vision and method; (5) students are accustomed to the traditional and established ways of thinking and rules to consider and resolve problems, lacking enthusiasm for innovation; (6) on the training methods of graduate education, too much attention have been paid on the intellectual factors while non-intellectual factors are not enough. 


\section{The Systemic FrameWORK OF POSTGRAdUATES' INNOVATION ABILITY}

Postgraduate innovation training is a system construction that a system of cultivating innovation ability and quality assurance shall be established in all-round, whole-process and full participation. According to the method of system theory, in terms of management innovation, curriculum reform, teaching methods innovation, scientific research and quality of dissertation writing, a quality assurance system of graduate student's cultivation aiming at promoting the student's innovative abilities is constructed as shown in figure 1 .

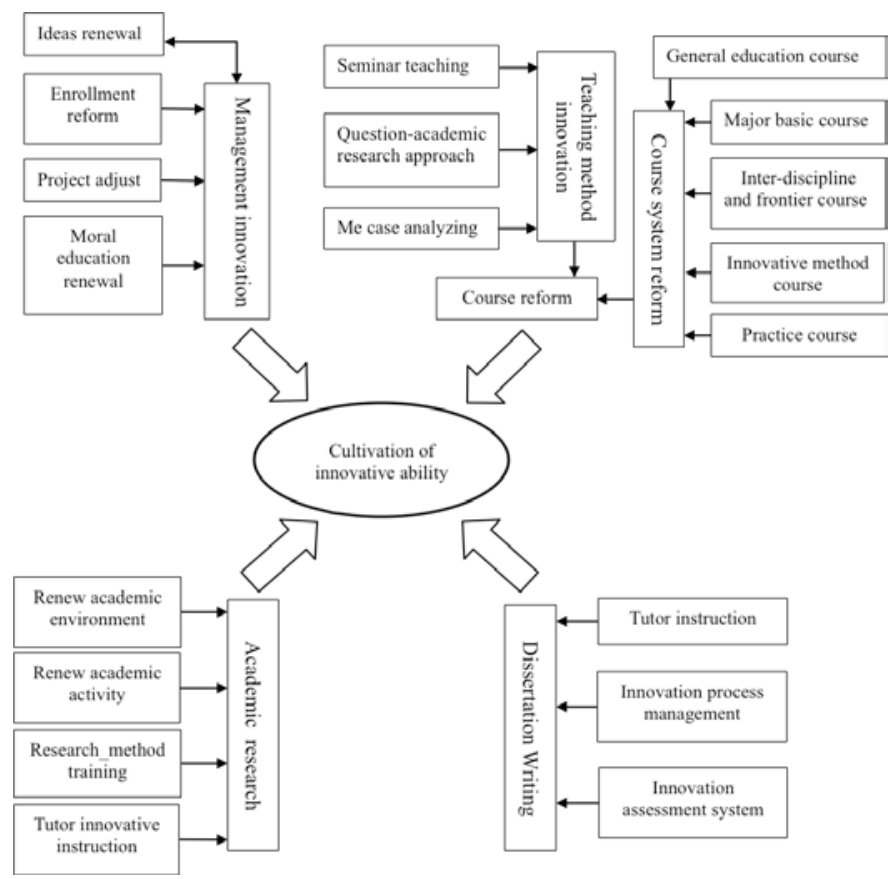

Fig. 1. Quality assurance system of cultivation of postgraduates' innovative ability

\section{The STRATEgIES OF QUALITy AsSURANCE OF POSTGRADUATES' CULTIVATION THE TEMPLATE}

\section{A. Renew the Education Ideas}

Traditionally, the cultivation of postgraduate in China's university is most based on discipline, inheritance and mentality oriented educational ideas which are not adapted for the innovative talents cultivation. It shall be gradually renewed by the ideas of educating, innovative oriented, coordinated development of mentality and non-mentality, such as: (1) on the concept of knowledge, not only the explicit knowledge of books but also the implicit knowledge of experience shall be fully acknowledged, the new concept of cross-discipline shall be established to realize the harmonious unity of knowledge acceptance, innovative ability training and overall quality improvement. (2) On the concept of mentality, the ability of autonomy learning, research, thinking, expressing and organized management shall be emphasized to promote the student's innovative ability. (3) On the concept of development, the non-mentality factors such as student's motivation, affection, personality and special skills shall be highlighted in the process of education to promote coordinated development of mentality and non-mentality factors. (Qu and Zhang, 2013)[5]

\section{B. Build an Enrollment Mechanism of Selecting Innovative Talents}

The quality and quantity of students is the basis of the cultivation of postgraduates and the quality of students is directly associated with the cultivation of innovative ability and affecting the whole process of education. Thus, the enrollment policy of postgraduates is the quality assurance of source of students.

The representative recruitment methods of postgraduate student in the world today are English, French, German's method (European style) and the American method. With respect to the European method, the admission process is an interactive process of two-way choice between teachers and students without entrance exam. Students need to choose a tutor in advance and submit a research plan during the postgraduate studying. With acceptance of the tutor and approval of the relevant departments of the school, the students can formally registered (Zhao, 2004)[2].

As for the American universities, it generally requires the applicant to pass a standardized test (such as GRE), some subjects such as business management, law also require the applicant to participate specialized examination organized by the testing service institutions, and submit the relevant application materials (including bachelor or master's stage proof of grades, letters of recommendation from two professors and research plan, etc.) within due date to the university's graduate school where the preliminary qualification audit is conducted. After passing the assessment and interview by the admission committee of the school, the matriculation is permitted.

Comparing the above two methods, the European method emphasize more on the research ability, research area and personality of applicant, while the American method gives more weight on the background, potential and comprehensive quality. (Xie, etc. 2005)[1]

In recent years, some domestic universities with autonomous enrollment of graduate student have carried out tentative reform on enrollment policy by means of adjusting weight of the written test and the interview test. In the secondround exam, the research ability and comprehensive quality of students have been strengthened. However, these reforms still need to be improved by adopting foreign successful experiences.

First of all, the written examination shall be improved, focusing on students' foreign language, politics, mathematics, professional and basic course grades. In additional to basic course grades, the academic achievement and experience during the university studying shall be examined, for the academic master and doctor candidates, recommendation and intended research plan of postgraduate studying are required to submitted. After passing the interview test with instructor and 
approved by relevant departments of the school, the matriculation is permitted.

Secondly, allow the tutors to broaden autonomous enrollment of graduates. The tutors are entitled to choose students with enrollment qualification, implementing the cultivation of student's innovation ability according to their aptitude.

Thirdly, reform the scope of enrollment. In order to avoid inbreeding phenomenon of graduate students, the university students shall be appropriately reduced and a mutual sending mechanism between universities shall be established to ensure outstanding students continuing education in different education environment.

Finally, encourage students to apply for cross-discipline examination. Different discipline has different cultural atmosphere, cross-discipline students have different view for the same problem with broad vision of knowledge which is beneficial to the cultivation of innovation ability.

\section{Strengthen the Students' Essential-Qualities-Oriented Education, Stress on Individuality Development}

Essential-qualities-oriented education aims to cultivate "libero" with all-round development, and comprehensive development is the foundation for the individual to carry out innovative activities. Essential-qualities-oriented education for the cultivation of the talent is not limited to professional knowledge and technique, also lies in facilitating students to form the comprehensive knowledge structure and promote healthy development in affection and volition.

Essential-qualities-oriented education and esteeming the student's individuality development are important parts of the cultivation of the student's innovative ability. Attaching great importance to the development of the student's individual independence indicates that students do not rely on others but think and act independently. Although independence is not equivalent to creativity, it is fair to say that creative talents always have strong independence.

The cultivation of graduate students of modern university shall not ignore the individual differences of students. In contrary, the differences of individual shall be taken as a resource to develop, providing every student with development opportunities and conditions, attaching importance to students' personality implementing education according to their aptitude to cultivate innovative talents.

\section{Implement Classified Cultivation Mode and Uphold Quality Concept of Pluralism}

The current graduate student training mode of "one size fits all" and "unification" ignores the discrepancy of the varied levels and types of postgraduate student's cultivation. It is against individualized education and cultivation of innovation ability, which shall be examined by the specific training institutions according to specific situation instead of following one standard and model to regulate the cultivation of postgraduate students.
Initially, the cultivation mode of mater students shall be diversified, forming multi-type development pattern of academic, practical and professional model. For talents of academic master, as they are primary resource of qualified student for doctoral education, master-doctor continuous study program can be implemented to lay the foundation for the cultivation of innovative ability in the future Dr. Period. As for applied talents, cultivation of their ability to solve practical problems shall be emphasized.

Secondly, the doctoral education should be given priority to cultivate creative talents as the cultivation base of innovative talents (Fan Delin, 2001)[6]. Under specified length of present education system, in order to finish dissertation in due time, many graduate students are often not willing to choose subjects with high difficulty and heavy workload which exerting impact on innovation of the dissertation. Therefore, it is imperative to adopt elastic length for postgraduate education, 2-4 years for mater students, 3-6 years for doctoral student, held by the training institutions. Extending the length of schooling is allowed for the students selected a topic with more difficulties and heavy work. For the graduate students selected paper topics with high application, allow them working while writing essays after finishing course study, and return to school complete the dissertation within the prescribed time.

Finally, establish incentive mechanism for graduate students via the policy of "coming in easily and out strictly" and adopting elimination system. Through the selection of training high quality graduate student, the academic innovation spirit of postgraduates is aroused. Some domestic universities have carried out mechanism of medium selection through competition which is a kind of beneficial attempt despite low elimination rate.

\section{E. Reform the Teaching Contents and Curriculum System}

According to cultivation plan of first grade discipline, improve the cultivation plan gradually by broadening the research areas and encouraging the students to select courses within the range of first grade discipline, even cross-discipline course selection is permitted. It not only enables them to fully absorb new achievements, methods and technologies in the relevant fields, but also enables them to have a broad thinking ability and contribute to make creative achievements in his own or relevant field.

By updating the teaching contents and optimizing curriculum system, establish a loose type education structure and comprehensive curriculum system in accordance with the policy of "scientific, standardized, widen". The system shall contain reasonable proportion of courses structure, such as proportion of politics, foreign languages, computer and other courses, the proportion of the basic course, professional basic course and specialized course, proportion of knowledge structure of specific and relevant major, elective and arbitrary elective courses as well as the proportion of the time structure of scientific knowledge learning and the thesis research.

Dilute the concept of teaching materials and advocate students learning from diversified forms. Teachers provide a number of reference books and courses index related papers, as well as provide corresponding outline data and a certain 
amount of influenced papers in the related discipline to the students. By reading the textbooks and following development and practical application of new theory related to the course, the innovative ability of student is cultivated naturally.

\section{F. Reform the Teaching Methods and Contents and Promote Seminar-Style Teaching}

It is needed to combine three ways of instructing, counseling and discussing to change the traditional cramming method of teaching. Firstly, teachers shall illustrate the basic concepts, theories, ideas and key points of the course and introduce the historic development, research method and the latest development trends of the subject in a relative short period; then teachers provide students with learning outline, including the basic framework or the reference topics of the course and some references relate the discipline. A primary way to check the level of reading comprehension of students is seminar. Based on the teaching contents, students are required to choose a research topic, searching relevant data and writing reading report after class, making presentation in class and discussing with teachers and students, finally the teacher comments on the presentation. In general, in the junior grade of postgraduate, the content of the seminar can focus on learning and research the important literature related disciplines and examining the ideas and methods of the authors while the senior graduate students is given priority to the research question. Students can make an appointment with teachers to consult the problems in the process of reading, topic selecting and other academic activities.

\section{G. Create Knowledge Innovation Mechanism and Favorable Atmosphere}

Firstly, an encouragement mechanism for outstanding students shall be established in universities, such as carrying out assessment activities and special scholarship for outstanding students. In the process of assessment, the practice of equalitarianism and rotation shall be precluded, providing more support to the research of excellent master's dissertation. Under the condition of insufficient investment in domestic education, individual talents should be given priority support and guarantee based on good quality of general master's cultivation (Cao Jian, 2012)[3].

Secondly, favorable academic atmosphere shall be created, encouraging students thinking in a free and original way in their academic field.

Academic activities such as lecture, seminar and intercommunions shall be organized irregularly. Academic communication is in a variety of forms, on the one hand, the domestic and foreign well-known experts can be invited to give lecture presentation; on the other hand, we can send students to participate in domestic or international academic conference. Great importance shall be attached to cultivation of student's innovative thinking in the process of cross-discipline academic exchange, encouraging the student to learn from academic communication and capture more innovation opportunities with broaden academic vision.

\section{H. Implement Collective Guidance System}

One tutor teaching one student is a typical instructed way in China's university. Students only have one chance to choose the tutor during the postgraduate studying in this cultivation pattern, which will make great influence on the whole study in case non-mentality such as personality incompatible with the tutor. When the student found that he was not suitable for the present tutor's guidance, it is hard to change other teacher. Other shortcomings of this patter are such as the knowledge range is relative narrow and the time for completing the dissertation is long or students take their own course as the tutor is quite busy.

Therefore, to strengthen the cultivation of student's innovation ability, the instructed way of postgraduates shall be reformed by implementing collective guide way of tutor group. The collective instructing method is beneficial to learn the strong points of all the teachers and broaden the academic vision and knowledge. "Double tutors" system in British shall be adopted, one of which is normally an associate professor to instruct big problems and provide funds for academic research while another tutor is generally a middle-aged lecturer to instruct specific problems during the schooling period. Tow tutors usually have same research topic and interest and guide student together.

In respect of interdisciplinary and university-enterprise cooperation, the successful practices in the United States shall be adopted, the teachers group are responsible for the guidance of graduate students. By bringing in experts from domestic and abroad to compose an instructed group for postgraduate education, encourage collective guidance and joint training graduate students to make them learn from each other and broaden academic view. After nearly a year of study, students and tutors are get to know each other and the relationship between them is determine by two-way choice. When $\mathrm{PhD}$ students and his instructed professor are defined, they will choose 3-5 professors in different areas and at least one professor from other university to compose the instructor committee. This pattern of group guidance contribute to provide students with more academic research opportunities and learn advantages from different professors and strengthen the cultivation of student' $s$ innovative ability.

\section{Strengthen the Practice of Postgraduate}

The cultivation of innovation ability cannot be separated from practice. Practice activities mainly include the production practice, the academic practice and scientific practice. In the process of the cultivation of graduate students, we shall take different practice training mode according to different students to improve the requirements of the production practice of students (especially the engineering graduate students)

Academic practice includes academic exchanges at home and abroad, academic report, consulting literature, holding seminars, writing papers, etc. These practices contribute to broaden the students' academic view and access to the latest academic trends, forefront theory and technology as well.

Research practice mainly refers to experiment research and dissertation writing which are pivotal to cultivate innovative 
ability of graduate student. Only through independent research and practice can Students cultivate and improve their innovation ability.

\section{J. Stress on the Innovative Level Of Dissertation Writing}

The topic of postgraduate's dissertation shall be reflected the innovative achievements and forefront level of discipline. The selection of thesis topic shall be in conjunction with the research subject and development of the tutor. Writing literature review is a basic skill for dissertation writing as well as a process of acquiring the latest research achievements at home and abroad and proposing their own innovative ideas. In addition, it is needed to examine whether the technical route of the paper is reasonable, research method is proper, research proposal is complete and research condition is qualified or not.

It is necessary to be strict with management of essay writing process by adopting anonymous appraisal system and rule of tutor avoidance to ensure objectivity of evaluation.

To encourage students improve the quality of the dissertation, the assessment of good papers shall be put forward. In conjunction with assessment of excellent students, the student and tutor who make innovative achievement shall be rewarded. For boosting pressure of paper writing, inferior eliminated mechanism shall be carried out with prescribed elimination rate.

\section{REFERENCES}

[1] Xie, F., Wang, B.Y., and Li, H.P., "The inner mechanism and implication from the way of postgraduate education in Germany and America (In Chinese)", Journal of institute of higher education research, vol.6, pp.38-44, 2005.

[2] Zhao, B., "The cultivation of innovative ability of postgraduates adopting international experience (In Chinese)", Journal of Shenyang Institute of Aeronautical Engineering, vol.6, pp.113-115, 2004.

[3] Cao, J., Rui, G.Q., and Cao G.L., "Thought on construction of comprehensive incentive mechanism of graduate student education (In Chinese)", Journal of higher education in Jiangsu province, vol.3, pp.112-116, 2012.

[4] Wang, R.L., Wang, L.J., "Research on innovation ability of master student based on the national innovation system (In Chinese)", China's higher education research, vol.10, pp.37-39, 2012.

[5] Qu, H.D., Zhang L.P., "Thoughts on construction of quality guarantee system of graduate education (In Chinese)", Journal of higher education in science and technology, vol.6, pp.26-29, 2013.

[6] Fan, D.L., "Research on quality assurance system of doctor students (In Chinese)", Journal of higher education in Heilongjiang province, vol.5, pp.71-72, 2001.

[7] Wang, R.F., Chen, J., and Li, F.Y., "Survey on innovative quality and capability of graduate students (In Chinese)", Journal of degree and graduate education, vol.5, pp.27-29, 2001. 